\section{The atmosphere from space}

\section{J.T. Houghton}

Satellite Sensing of a Cloudy Atmosphere: Observing the Third Planet.

Edited by Ann Henderson-Sellers.

DURING the past 20 years there has been considerable growth in the exploitation of satellite platforms for mounting remotesensing instruments to investigate the structure of the atmosphere and the Earth's surface. The great advantage of the satellite, of course, is the ease with which continuous global coverage can be achieved.

In this book, articles by different authors address various aspects of remote sensing. The first two chapters provide an introduction; radiation quantities are defined and details given of the interactions of radiation (especially visible radiation) with the atmosphere and its various components. Brief descriptions of relevant satellites are included, and there is an introductory account of cloud observations. Three of the six later contributions are concerned with various aspects of the sensing of clouds - their identification and characterization, their influence on the radiation budget, and cloud-cryosphere interactions. Other chapters deal with temperature profile, with problems of the sensing of land and ocean surface features (a particularly useful chapter), and with tropospheric chemistry.

To my mind, the book tends to fall Taylor \& Francis: 1984. Pp. 336. \$18, \$40. sounding of the atmosphere's vertical

between two stools. On the one hand the chapters are not sufficiently thorough and comprehensive nor are they well enough referenced to be used as authoritative reviews. On the other hand the book lacks the cohesion and flow of exposition demanded of a textbook. There are also some surprising omissions and inclusions. Despite the introductory emphasis on the "water planet", virtually nothing is said about measurement of water-vapour and very little about precipitation measurement. Further, the importance of water in its various forms in determining the nature of the atmospheric circulation is not discussed - yet a chapter is included on tropospheric chemistry which, apart from a passing mention of a satellite instrument

\section{Unusual enzymes}

\section{Pierre Desnuelle}

Lipases. Edited by Bengt Borgström and

Howard L. Brockman.

Elsevier: 1984. Pp. 527. \$123, Dfl.320.

LIPASES share with phospholipases the unique ability to hydrolyse very rapidly water-insoluble substrates which form plurimolecular aggregates separated from water by an interface. Our knowledge of their properties has advanced enormously in recent years, and fully justifies the publication of a book on the topic.

Lipases was planned and partly written by B. Borgström and H.L. Brockman, long-standing experts in the field. It begins with a general account of the behaviour of lipid and water molecules at interfaces, and of the way amphiphilic lipids associate in

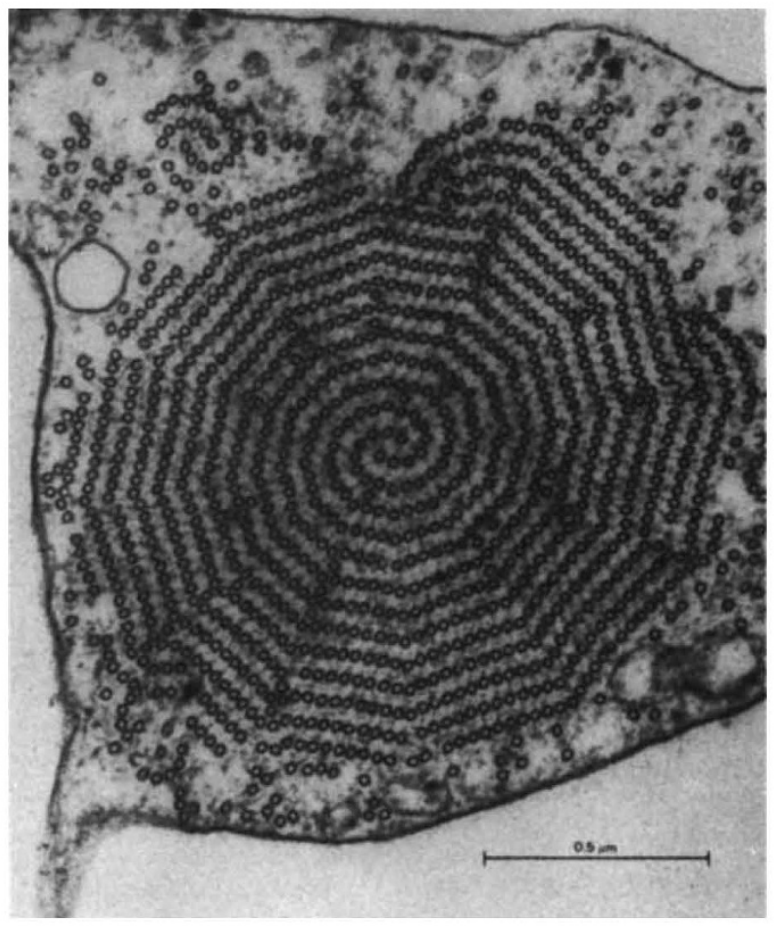

(no details or results included), has no relevance to the overall satellite theme. A further annoying feature is that although in Chapter 2 a page and a half is devoted to a table giving careful definition of radiation quantities and symbols, quite different nomenclature is used in Chapter 5.

The book therefore is not, unfortunately, likely to find widespread application as a student text. But, despite its unsatisfactory features, research workers in the remote-sensing field will find that it contains some useful material and will be pleased that it is available at a price they can afford.

J.T. Houghton is Director General of the Meteorological Office, Bracknell, Berkshire.

the presence of water. This useful introduction is followed by nine chapters on mammalian lipases and four which deal with "other" lipases.

Four of the early contributions are devoted to digestive lipases in mammals. The first covers lingual lipase, a newcomer to the lipase family which initiates fat splitting in the mouth and stomach, after which come two chapters on pancreatic lipase and on colipase. Pancreatic lipase has served as a model for the study of "interfacial enzymology" in heterogeneous systems; curiously enough, its interfacial adsorption is hindered by bile salts and a small protein cofactor, colipase, is required to anchor it at the interface under physiological conditions. The third digestive lipase is pancreatic carboxyl ester lipase (more commonly known as carboxylesterase or cholesterol esterase). Unlike a "true" lipase, it cleaves dissolved substrates and is activated by bile salts.

Particular emphasis in the book is laid on two tissue lipases. One is lipoprotein lipase, which acts at the capillary endothelium to remove circulating chylomicrons and VLDL from the plasma, and is activated by apolipoprotein CII. This enzyme is also present in milk, together with an enzyme similar to carboxylesterase. The other tissue lipase covered in some detail is adipose tissue lipase (also called hormonesensitive lipase) which is involved in the mobilization of triglycerides from the adipose tissue, its action being controlled by a cyclic AMP-mediated phosphorylation. Finally, there are accounts of lipases from plants, fungi and bacteria, special reference being made to structure, specificity and practical applications.

Most of the chapters are authoritative yet readable, and each of them is followed by a thorough list of references. As well as its natural audience of enzymologists and biologists engaged in research on lipid metabolism, the book will interest clinicians and advanced students in biology and medicine.

Pierre Desnuelle is Professor Emeritus of Biochemistry at the University of Marseilles. 